followed by fall (13\%) and MVC (12\%). Among pedestrians, diffuse axonal injury, subarachnoid haemorrhage, skull fractures and mortality were significantly lesser in PATBI. Alcoholic pedestrians had higher proportion of polytrauma $(\mathrm{p}=0.02)$. In fall-related injury, alcoholic patients had lower proportion of intubation $(p=0.02)$ and brain oedema $(p=0.05)$. MVC-related PATBI patients had more intrahemisheric haemorrhage but less skull fracture $(p=0.02)$ and epidural haemorrhage $(0=0.03)$.

Conclusions the proportion of positive alcohol among TBI is high; however, it shows better hospital survival. Screening of alcohol among TBI gives important clues in terms of the type of TBI lesions in relation to different mechanisms of injury. Early identification of alcoholic status and its early management could be reflected in better outcome among this set of population. This analysis is limited with the lack of long-term follow-up and patients disabilities.

\section{KNOW THE SCORE: EVALUATION OF AN INTERVENTION TO REDUCE LEVELS OF DRUNKENNESS IN A UK NIGHTLIFE AREA}

Zara Quigg, Kat Ford, Nadia Butler, Katie Hardcastle, Karen Hughes. Centre for Public Health, Liverpool John Moores University, Liverpool, UK

\subsection{6/injuryprev-2016-042156.632}

Background In the UK the sale of alcohol to drunk people is illegal; however drunkenness remains common in nightlife environments. To address drunkenness in a UK nightlife area, an intervention was implemented to increase awareness of such legislation and to support bar staff compliance with the law. Methods Pre- $(\mathrm{n}=260)$ and post- $(\mathrm{n}=318)$ intervention nightlife patron surveys were implemented exploring: drinking behaviours; expectations and tolerance of drunkenness; and knowledge of the law. The post-intervention survey additionally explored public awareness and perceptions of the intervention, and potential behavioural change as a result of the intervention.

Results The majority of pre-intervention survey participants had consumed alcohol; 63\% of drinkers had preloaded. Drinkers expected units of alcohol consumed over the course of the night was 17.9 units. The majority expected their, and other people's, level of drunkenness to be high when leaving the city's nightlife. Over half believed that if someone was drunk and tried to get served alcohol in a bar in the city centre they would be served. Four in ten thought it was legal for a bar server to sell alcohol to someone who was already drunk. Post-intervention: significantly more participants knew that it is illegal for a bar server to sell alcohol to someone who is already drunk; significantly less agreed that getting drunk is socially acceptable; and significantly less reported preloading.

Conclusions The intervention presents an important step in working towards preventing the sale of alcohol to drunks and reducing associated harms. The evaluation suggests that the intervention may have increased knowledge of the laws around the service of alcohol to drunks amongst nightlife users, changed the perceived acceptability of drunkenness and decreased preloading. Despite this, post-intervention surveys illustrated that excessive alcohol consumption and drunkenness remain key features of the night-time economy.

\section{DIVERGENT TRENDS IN EMERGENCY DEPARTMENT VISITS FOR POISONINGS BY INTENT IN VÄRMLAND, SWEDEN}

Syed Moniruzzaman. Risk Management, Karlstad University, Sweden

10.1136/injuryprev-2016-042156.633

Background Poisoning is one of the key categories of adverse events that cause a large number of hospital admissions. With the recent availability of detailed injury data it is possible to provide useful information about the demographic and clinical characteristics of patients with poisonings that warrant additional analysis and is important for policy implications. The aim of this study is to review emergency department (ED) visits for poisonings reported through Injury database (IDB), Värmland, and to evaluate demographic and clinical characteristics of poisonings by intent.

Methods Using data from the IDB, Värmland, we compared poisoning trends by poisoning intent (accidental vs suicide attempt) from 2007 to 2013 . We also analysed poisoning cases by age, sex and mechanism of intoxication using distribution tabulation and logistic regression.

Results According to the IDB data, ED visits for suicide attempt by poisonings showed continuous increases from 2007 to 2013. Continuous and somewhat sharp increases were seen in suicide attempt by poisonings resulting from prescribed drugs during the period. By contrast, levelling off or steady declines in accidental poisonings were observed both in all poisoning cases and poisonings resulting from prescribed medicine. Age, sex, year and mechanism of intoxication were significantly associated with suicide attempt by poisonings among the ED visits due to poisoning cases.

Conclusions Inequalities in suicide attempt by poisonings exist between ages and sexes. Significant increasing trends of these self-inflicted poisonings, especially resulting from prescribed medicine, show in ED visits for poisonings when analysing IDB, Värmland database, which must be further compared with other Swedish IDBs to be resolved. The IDB data provide an opportunity to better understand poisoning mechanisms and associated risk factors, which is important for poisoning prevention practice and research.

\section{Arctic safety and occupational safety}

\section{Post Tue 2.2}

\section{REDUCING SLIPPING AND FALLING ACCIDENTS IN MINING AND QUARRYING INDUSTRY IN THE ARCTIC AREA BY SELCTION OF SUITABLE SAFETY FOOTWEAR}

Mikko Hirvonen. Finnish Institute of Occupational Health, Finland

10.1136/injuryprev-2016-042156.634

Background Accidents related to slips, trips and falls represent roughly one fourth of the total accidents in the mining and quarrying industry in Finland. According to a recent estimate, in Finland, an accident involving a fall costs about $6000 €$ on average. Working in the northern open pit mines exposes the workers in harsh weather conditions where pedestrian walkways are often very slippery because they are covered by ice and snow. Therefore it is essential that the footwear used by the workers has good grip in those conditions. 
Description of the problem Footwear selected to be used in the mine work is normally based on the risk assessment because some workers do occasionally work that includes welding the footwear are selected on those based on those criteria's. Most commonly the footwear soles are selected so that they are resistant to hot contact (HRO) according the PPE-footwear standard. This leads to the selection of footwear which sole are made from dense materials like nitrile rubber. Using of those dense polymers like can be problematic in the arctic area because the slip resistance of the footwear soles made from dense materials is found to be poorer than footwear made from softer soling materials. The cold climate can increase the hardness of the soling material which makes footwear even more slippery.

Slip resistance, i.e. dynamic coefficient of friction (DCOF) of the footwear was measured in laboratory by using FIOH's own laboratory device slip simulator. Measurements were carried out according the parameters defined in the standard EN ISO 13287: 2012 Personal protective equipment-Footwear-Test method for slip resistance. The standard method was modified only by using smooth ice surface as a test surface. Ten consecutive measurements were done by each footwear model. The mean value and standard deviation was calculated. In addition the footwear was pre-conditioned in the climatic chamber at the temperature of $20 \mathrm{C}^{\circ}$ for four hours in order to see how the hardening of the sole materials affects to the slip resistance. Hardness of the sole was measured by using hardness tester with Shore (A) hardness scale.

Four different footwear were selected and collected form the mines participating in the project. Three of those footwear were safety footwear according EN ISO 20345: 2011 they were halfknee height leather footwear designed for winter conditions. One sample was rubber boot from Russia and it was not classified as safety footwear according to EN or ISO standards. Additionally six different safety footwear for winter conditions were selected in order to compare level of performance the slip resistance of footwear used in mines to the winter footwear available in the market.

Results Samples collected from the four mines got almost equal DCOF levels than the winter safety footwear selection from market when they were measured without pre-conditioning, but the DCOF values were 39\% lower compared to winter safety footwear selection when the samples were pre continued in climatic chamber. Hardness of the footwear sole increased 26\% in average because of the pre-conditioning in cold.

Conclusions Footwear currently used in the four mines have reasonable good slip resistance compared to footwear's available in the market, but their fiction level is strongly dependent of the temperature. For safety reasons, it would be advisable to use footwear sole materials which are not so much affected by the temperature changes especially in the artic area mines.

\section{PHYSICAL STRAIN OF MAST AND POLE WORK IN ARCTIC CONDITIONS}

${ }^{1}$ Juha Oksa, 'Sanna Hosio, ${ }^{1}$ Hannu Rintamäki, ' Sirkka Rissanen, ${ }^{2}$ Panu Oksa. ${ }^{1}$ Finnish Institute of Occupational Health, Oulu, Finland; ' ${ }^{2}$ Finnish Institute of Occupational Health, Tampere, Finland

\subsection{6/injuryprev-2016-042156.635}

Background Since physical strain during mast and pole work is not known this study evaluated the level of muscular, cardiorespiratory and thermal strain of mast and pole workers with special emphasis on arctic conditions, winter.
Methods Fourteen voluntary mast and pole workers participated. We measured their muscular strain using electromyography, expressed as percentage in relation to maximal EMG activity (\% MEMG). We estimated $\mathrm{VO}_{2}$ from $\mathrm{HR}$ measured during work (using individual $\mathrm{VO}_{2}$ - $\mathrm{HR}$ relationship) and expressed it as $\%$ $\mathrm{VO}_{2}$ max. To quantify thermal strain skin and deep body temperatures were measured using temperature sensors and telemetric pill and receiver.

Results We found the highest average muscular strain in the wrist flexor $(24 \pm 2 \%$ MEMG $)$ and extensor $(21 \pm 1 \%$ MEMG $)$ muscles, exceeding the recommendation of 14\% MEMG. Average cardiorespiratory strain was $48 \pm 3 \% \mathrm{VO}_{2}$ max. Nearly half $(40 \%)$ of the subjects exceeded the recommended $50 \% \mathrm{VO}_{2} \max$. Winter condition increased both muscular and cardiovascular strain on average by 4 and 2\%, respectively. Deep body temperature varied between 36.8 and $38.0^{\circ} \mathrm{C}$ and mean skin temperature between 28.6 and $33.4{ }^{\circ} \mathrm{C}$. Cooling was most pronounced in extremities during winter. Lowest single temperatures in middle finger, hand and big toe varied between 6.4 and 18.5, 9.4 and 24.9 and 15.4 and $24.6^{\circ} \mathrm{C}$, respectively.

Conclusions This field study showed that workers may be at risk for local and/or systemic muscular and cardiorespiratory overloading (the winter enhancing this effect) and thus for excessive fatigue, reduced work efficiency and increased risk for musculoskeletal symptoms. Generally, thermal strain remained at a tolerable level.

\section{STAY STANDING - WINTER SAFETY CAMPAIGN FOR PEDESTRIANS}

${ }^{1}$ Kaarina Tamminiemi, ${ }^{2}$ Tiina Tikkanen. ${ }^{1}$ SOSTE Finnish Federation for Social Affairs and Health, Finland; ${ }^{2}$ Finnish Red Cross, Finland

\subsection{6/injuryprev-2016-042156.636}

Background Stay Standing - Winter Safety Campaign for Pedestrians is part of the Implementation Project on Prevention of Home and Leisure Injuries. SOSTE Finnish Federation for Social Affairs and Health is the chairman of the campaign and Finnish Red Cross is coordinating the entire project. Partners in the campaign include various non-governmental, governmental and private organisations. Partners are working in the fields such as injury prevention, traffic safety and weather and climate conditions.

Description of the problem Each winter every four out of ten of the Finns (total population 5.2 million) are slipping due to icy weather conditions. Half of them get injured. Slipping causes plenty of minor injuries. Slipping also causes severe injuries such as fractures, dislocation of joints and head injuries, which may lead to long term disability. Each year more than 5000 people are hospitalised overnight during icy or snowy weather conditions. Slipping does not vary among the adult age group.

Results The Campaign promotes safety through informing the associated risks, which rise throughout the winter. The campaign also provides information on risk reduction. January is the most active month of the campaign. The target group is chosen each year. Also, different communication channels for the campaign are chosen each year: TV-spots, radio, digi screen, printed material and seminars.

Conclusions Conducting the campaign in collaboration with various governmental and non-governmental organisations has been very useful. By effective communication, the campaign has 